\title{
Feasibility and Acceptability of a Culturally- and Linguistically-Adapted Smoking Cessation Text Messaging Intervention for Latino Smokers
}

\section{OPEN ACCESS}

Edited by:

Cyrille Delpierre,

INSERM U1027 Epidémiologie et analyses en santé publique: Risques,

Maladies Chroniques et Handicap, Université Toulouse III Paul

Sabatier, France

Reviewed by:

Nadia Mignolli,

Italian National Institute of Statistics

(ISTAT), Italy

Julia Katherine Rohr,

Harvard University School of Public

Health, United States

*Correspondence:

Ana Paula Cupertino

paula_cupertino@urmc.rochester.edu

Specialty section:

This article was submitted to Inequalities in Health,

a section of the journal

Frontiers in Public Health

Received: 17 December 2019 Accepted: 26 May 2020

Published: 30 June 2020

Citation:

Cartujano-Barrera F, Sanderson Cox L, Arana-Chicas E.

Ramírez M, Perales-Puchalt J,

Valera P, Díaz FJ, Catley $D$,

Ellerbeck EF and Cupertino AP (2020)

Feasibility and Acceptability of a Culturally- and Linguistically-Adapted

Smoking Cessation Text Messaging Intervention for Latino Smokers. Front. Public Health 8:269.

doi: 10.3389/fpubh.2020.00269

\section{Francisco Cartujano-Barrera ${ }^{1}$, Lisa Sanderson Cox ${ }^{2}$, Evelyn Arana-Chicas ${ }^{1}$, Mariana Ramírez ${ }^{2}$, Jaime Perales-Puchalt ${ }^{2}$, Pamela Valera ${ }^{3}$, Francisco J. Díaz ${ }^{4}$, Delwyn Catley ${ }^{5}$, Edward F. Ellerbeck ${ }^{2}$ and Ana Paula Cupertino ${ }^{6 *}$}

\begin{abstract}
'Department of Cancer Prevention and Control, Hackensack University Medical Center, Hackensack, NJ, United States, ${ }^{2}$ Department of Population Health, University of Kansas Medical Center, Kansas City, KS, United States, ${ }^{3}$ Department of Urban-Global Public Health, Rutgers University, Newark, NJ, United States, ${ }^{4}$ Department of Biostatistics, University of Kansas Medical Center, Kansas City, KS, United States, ${ }^{5}$ Center for Children's Healthy Lifestyles \& Nutrition, Children's Mercy Kansas City, Kansas City, MO, United States, ${ }^{6}$ James P. Wilmot Cancer Institute, University of Rochester Medical Center, Rochester, NY, United States
\end{abstract}

Objective: Assess the feasibility and acceptability of a culturally- and linguistically-adapted smoking cessation text messaging intervention for Latino smokers.

Methods: Using a community-based strategy, 50 Latino smokers were recruited to participate in a smoking cessation pilot study. Participants received a 12-week text messaging intervention and were offered Nicotine Replacement Therapy (NRT) at no cost. We assessed biochemically verified abstinence at 12 weeks, text messaging interactivity with the program, NRT utilization, self-efficacy, therapeutic alliance, and satisfaction.

Results: Participants were 44.8 years old on average (SD 9.80), and they were primarily male $(66 \%)$ and had no health insurance $(78 \%)$. Most of the participants were born in Mexico (82\%) and were light smokers (1-10 CPD) (68\%). All participants requested the first order of NRT, and 66\% requested a refill. Participants sent an average of 39.7 text messages during the 12-week intervention (SD 82.70). At 12 weeks, 30\% of participants were biochemically verified abstinent ( $88 \%$ follow-up rate) and working alliance mean value was 79.2 (SD 9.04). Self-efficacy mean score increased from 33.98 (SD 10.36) at baseline to 40.05 (SD 17.65) at follow-up $(p=0.04)$. The majority of participants $(90.9 \%$, 40/44) reported being very or extremely satisfied with the program.

Conclusion: A culturally- and linguistically-adapted smoking cessation text messaging intervention for Latinos offers a promising strategy to increase the use of NRT, generated high satisfaction and frequent interactivity, significantly increased self-efficacy, produced high therapeutic alliance, and resulted in noteworthy cessation rates at the end of treatment. Additional testing as a formal randomized clinical trial is warranted.

Keywords: Latinos, m-health, smoking, smoking cessation, text messages 


\section{INTRODUCTION}

Tobacco use remains the leading preventable cause of disease and death among Latinos (1), the largest minority group in the United States (U.S.) (2). Of the $\sim 60$ million Latinos than reside in the U.S. (2), $9.8 \%$ are current cigarette smokers (3). Compared to both African Americans and non-Hispanic Whites, Latinos are less likely to receive advice to quit and utilize smoking cessation pharmacotherapy and counseling (49). According to the 2015 National Health Interview Survey, only $16.6 \%$ of Latinos have used cessation pharmacotherapy compared to $32.6 \%$ of non-Hispanic Whites (10). Use of counseling services to quit smoking is also lower in this group (5.1 vs. 6.9\%) (10).

A myriad of factors account for low utilization of smoking cessation treatment among Latinos. Overall, Latinos report a lack of knowledge about smoking cessation treatment options and perceive a lack of cultural sensitivity when smoking cessation resources are available in Spanish (11). Moreover, Latinos hold several misconceptions about smoking dependence and cessation and may tend to avoid pharmacotherapy, viewing smoking as a weakness rather than an addiction $(12,13)$. Moreover, non-adherence to smoking cessation pharmacotherapy has been identified as an important barrier to smoking cessation success among Latino smokers $(14,15)$. Despite these tobacco-related disparities, there are few effective smoking cessation interventions designed for Latino smokers (16), especially interventions that have the potential for high reach across the Latino community. Advancing treatment for Latino smokers demands accessible, effective, and culturally sound interventions.

The literature demonstrates that text messaging-based smoking cessation interventions are effective (17-22). Text messaging interventions have shown to increase self-efficacy and coping mechanisms by including content related to self-awareness, self-monitoring, and behavioral skill learning (22). Moreover, technology advancements allow for delivery of tailored messages based on individual motivational and behavioral needs to support smoking cessation (17). The effectiveness of smoking cessation text messaging interventions may be even greater among hard-to-reach, socioeconomically disadvantaged, and uninsured populations (18), such as Latinos. However, implementation of text messaging interventions among Latinos remains low despite the fact that Latinos are the highest users of text messages (23). Capitalizing on Latinos' fast adoption of mobile technology, an intervention that fosters engagement and trust through cultural congruency and addresses both pharmacotherapy use and behavior change skills to promote smoking cessation could dramatically reduce tobacco-related disparities. Cultural and linguistic congruence may increase the effectiveness of interventions by enhancing message processing and acceptance by participants $(24,25)$. The purpose of this pilot study was to assess the feasibility and acceptability of a culturally- and linguisticallyadapted smoking cessation text messaging intervention for Latino smokers.

\section{METHODS}

\section{Study Design}

This is a single-arm pilot study with 50 Latino smokers who received a culturally- and linguistically-adapted smoking cessation text messaging intervention and Nicotine Replacement Therapy (e.g., nicotine patches, gum, and lozenges; NRT). The study was based at JUNTOS Center for Advancing Latino Health, an academic and community partnership at the University of Kansas Medical Center (KUMC). Study procedures were approved and monitored by the KUMC Institutional Review Board (\#STUDY00002725). Participants were compensated a $\$ 30$ retail store gift card both at baseline and follow-up for their time and transportation.

\section{Recruitment}

Latino smokers were recruited by Promotores de Salud (Spanish for Community Health Workers) using community-based recruitment strategies (e.g., conducting presentations about the study, distributing program flyers and educational materials on smoking hazards, etc.) in venues with a high concentration of Latinos (e.g., Latino grocery stores, safety-net clinics, community centers, and churches) and word of mouth from participants and community partners. Recruitment started in March 2016 and ended in June 2016. Final 12-week follow-up assessment was completed in September 2016.

\section{Eligibility}

Individuals were eligible if they (1) self-identified as Hispanic or Latino, (2) were $\geq 21$ years of age, (3) smoked a minimum of 3 days in the past week, (4) had a cellphone with unlimited text messaging capability, and (5) were willing to complete a baseline and 12-week follow-up assessment. Individuals were not eligible if they (1) were currently enrolled in a smoking cessation program or using smoking cessation medication, (2) had an additional household member participating in this study, (3) consumed other forms of tobacco (including e-cigarettes), (4) were currently pregnant, breast-feeding or planning to do so in the next year, or (5) were planning to move from their residential city in the following 6 months.

\section{Screening and Consent}

Bilingual (English and Spanish) trained research staff determined participant eligibility. Individuals who were eligible to participate in the study were scheduled an in-person appointment by research staff. During the in-person appointment, staff discussed all aspects of study participation and confidentiality, answered any questions, and guided eligible smokers through the process of written informed consent. Eligibility assessment and consent were available in the participant's language of preference.

\section{Intervention}

Kick Buts is an American adaptation of Txt2stop, a smoking cessation text messaging intervention that demonstrated a 2 -fold increase in abstinence among study participants in New Zealand and United Kingdom (20, 21). Kick Buts follows principles from the Social Cognitive Theory (26), including motivational 
messages, behavioral-change support, and pharmacotherapy use (NRT). Kick Buts, available in English and Spanish, allowed three levels of interactivity:

1) Pre-scheduled standard messages. Messages were tailored to the participant's name(s) and their selected quit date. The text messaging system delivered these messages according to an algorithm based on four sequential phases of the quitting process: (1) Pre-quit (14 days); (2) Quit-day (1 day); (3) Post-quit Intensive (28 days); and (4) Post-quit Maintenance (8 weeks).

2) Keyword triggered standard messages. These messages consisted of automated responses sent immediately to participants who sent the program one of the following keywords: Alcohol, Crave, Relapse, Slip Up, and Stress. Participants could withdraw from the text messaging program at any time by texting the word Stop.

3) Personalized responses. The text messaging system had the ability to receive free texts (not keywords) from study participants. Trained research staff monitored, triaged, and responded (if needed) to text messages sent by participants. Responses occurred within $48 \mathrm{~h}$ of receiving the texts.

\section{Decision Support}

An additional new first text-based stage, Decision Support, was created and integrated with the already existing four stages of Kick Buts (pre-quit, quit-day, post-quit intensive, and post-quit maintenance). The aim of this 10-day stage was to enhance motivation and readiness among Latino smokers who were not ready to quit smoking. The Decision Support stage was informed from two web-based smoking cessation decision-making tools developed for Latinos in the U.S. (27) and Mexico (28). The Decision Support stage helped participants develop their quit plan, identifying "how" (e.g., type of medication) and "when" (e.g., quit date) they wanted to quit smoking. Participants were prompted to set up a quit plan after 3,6, and 9 days of enrollment by texting READY or LISTO. A trained research staff called participants $24-72 \mathrm{~h}$ after texting READY or LISTO to set up a quit date within a 2-week frame and their Nicotine Replacement Therapy (NRT) of preference. If a participant did not text READY or LISTO, they were called when the Decision Support stage ended. After the Decision Support stage, participants received the following progressive stages (pre-quit, quit-day, post-quit intensive, and post-quit maintenance).

\section{Cultural and Linguistic Adaptation of the Intervention}

Using the Cultural Accommodation of Substance Abuse Treatment framework (29), we adapted Kick Buts to Latino smokers. The aim of this framework is to enhance components of an intervention to increase congruency with the cultural norms of a specific group and adjust delivery mode (29). In accordance with this model, an initial pilot test with Latino smokers $(n=$ 20) was conducted (30). In that study, participants received a Spanish translated version of Kick Buts. Results of that study indicated that (1) text messages should address social support from family members, friends, and former smokers, and (2) the translation into Spanish should be improved (30). To address participants' feedback on social support, (1) new keywords (e.g., family and health) and (2) new standard messages elucidating vicarious experiences were developed. To address participants' feedback on the translation, a Community and Communication Advisory Board with members of different Latino nationalities was convened to review the message library and ensure the cultural and linguistic congruency of each message. Readability of final messages was assessed by stage using the Flesch-Kincaid and Fernández Huerta tests for English and Spanish, respectively (31-33). A Flesch-Kincaid score of 100-90, 90-80, or 70-80 indicates that the text readability in English is very easy (5th grade level), easy (6th grade level), or fairly easy (7th grade level), respectively $(31,32)$. A Fernández Huerta score of 100-90, 9080 , or $70-80$ indicates that the text readability is very easy (4th grade level), easy (5th grade level), or quite easy (6th grade level), respectively (33).

\section{Nicotine Replacement Therapy (NRT)}

The use of NRT followed the Clinical Practice Guidelines for Treatment of Tobacco Use (16). NRT (nicotine patches, gum, or lozenges) was offered to eligible participants at no cost. NRT was contraindicated and thus not offered to participants who (1) had a heart attack in the past 2 months, (2) had a stroke in the last 6 months, (3) had an arrhythmia or tachycardia, (4) had uncontrolled hypertension, and (5) were using Warfarin at the time of eligibility (16). At the end of the Decision Support stage, each participant received a 4-week supply of their NRT of preference mailed to their address. Participants were encouraged to start using their NRT on their selected quit-date, which was set at their baseline visit. At the beginning of the second week of the intervention, participants received text message prompts to request an NRT refill to continue treatment. If participants responded to the text prompts indicating interest in NRT, a 4or 6-week supply was shipped to their home.

\section{Assessments}

All assessments were completed in the language of preference of the participant. The in-person baseline survey collected sociodemographic variables such as gender, age, education level, country of birth, language spoken at home, marital status, and type of health insurance. Smoking-related variables collected included number of cigarettes per day (CPD), time to first cigarette, if they made a quit attempt in the previous year, smoking in the social network, contraindications of NRT, and the smoking self-efficacy questionnaire (SEQ-12). The SEQ-12 is a questionnaire measuring the confidence of smokers (current and former) in their ability to abstain from smoking in high-risk situations (34). The SEQ-12 consists of 12 items, and each item is rated on a 5 -point Likert scale $(1=$ not at all sure, $2=$ not very sure, $3=$ more or less sure, $4=$ fairly sure, and $5=$ absolutely sure) (34). SEQ-12 scores range from 12 to 60 with higher scores indicating greater self-efficacy (34).

Two brief surveys were done over the phone after baseline: (1) 24-27 h after the end of the Decision Support stage, and (2) $24-72 \mathrm{~h}$ after participants' quit date. The survey at the end of the Decision Support stage collected data on participants' 
quit date and NRT of preference. The survey after participants' quit date collected data on the receipt of NRT and participants' determination to quit smoking on their quit date (Did you try to quit smoking on your quit date?).

During the 12-week duration of the intervention, we assessed the frequency of text messages that participants sent to the program. Participants' texts were categorized as keywords and free-text response to the counselor.

Twelve weeks after enrollment, a second in-person assessment was conducted by trained research staff. Moreover, saliva samples and exhaled carbon monoxide (CO) were collected to verify cessation status. The survey collected data on self-reported prevalence of smoking abstinence, therapeutic alliance, and selfefficacy. Cotinine-verified 7-day point prevalence abstinence (no cigarettes in the past 7 days) at 12 weeks was the primary outcome. Cotinine verification was conducted using saliva samples with a cutoff point of $15 \mathrm{ng} / \mathrm{ml}$ cotinine $(35,36)$. If the participant was using NRT at the time of the 12-week assessment, exhaled CO (with a cutoff of $6 \mathrm{ppm}$ ) was used to verify smoking abstinence. Secondary outcomes were satisfaction with the intervention, therapeutic alliance, and changes in selfefficacy. Satisfaction measures included questions such as "How satisfied are you with the smoking cessation text messaging program?" Therapeutic alliance and self-efficacy were measured using the Working Alliance Inventory-Short Version (WAIS) $(37,38)$ and the SEQ-12 tests, respectively. The WAI-S is a questionnaire measuring three key aspects of the therapeutic alliance: (1) agreement on the goals of therapy, (2) agreement on the tasks of therapy, and (3) development of an affective bond (37). The WAI-S consists of 12 items, and each item is rated on a 7 -point Likert scale $(1=$ never, $2=$ rarely, $3=$ occasionally, $4=$ sometimes, $5=$ often, $6=$ very often, and $7=$ always) $(37,38)$. WAI-S scores range from 12 to 84 , with higher scores reflecting a stronger working alliance $(37,38)$.

\section{Analysis}

Frequencies were calculated for categorical variables. Means and standard deviations were calculated for continuous variables. For the primary analysis on smoking cessation, participants lost to follow-up were considered smokers. The secondary analysis on satisfaction, therapeutic alliance, and self-efficacy were conducted using complete case analysis, in which missing values in the outcome were considered to be missing. Self-efficacy at baseline and follow-up was compared using a paired sample $T$-test to examine differences. Associations between cessation and sample characteristics were analyzed using Chi-square tests. Fisher test was used when cells had expected counts $<5$.

\section{RESULTS}

The average readability score of final messages in English and Spanish was classified as "very easy". The reading levels of each text category were "very easy" (50\%) and "quite easy" (50\%). Scores averaged 80.01 (range 73.41-86.46, 6th-7th grade levels) and 83.39 (range 77.80-90.56, 4th-6th grade levels) using the Flesch-Kincaid and Fernández Huerta tests, respectively.
Readability levels were similar in English and Spanish for all stages of the text message library (see Table 1).

A total of 288 Latino smokers were identified. Among these, 186 were contacted and assessed for study eligibility; 115 were eligible to participate in the study. Overall, 53 Latino smokers consented to participate the study and completed the baseline assessment. Three smokers were removed from the study because they did not know how to send/receive text messages, resulting in 50 individuals enrolled in the study (Figure 1).

At baseline, participants' mean age was 44.8 years old (SD $9.80), 66 \%$ of the participants were male, $64 \%$ were married or cohabitating, $60 \%$ had completed high school education or greater, and the majority (78\%) had no health insurance. Most of the participants (82\%) were born in Mexico and 60\% only spoke Spanish at home. Most participants (68\%) were light smokers (1-10 CPD) and tried to quit in the past year (70\%). Half (52\%) of the participants smoked their first cigarette more than $60 \mathrm{~min}$ after waking up. A third of the sample (32\%) reported that none of their five closest family or friends smoked. The mean SEQ-12 score was 32.18 (SD 10.29), which is considered to be in the low to moderate range of self-efficacy for quitting smoking (see Table 2). All participants were eligible to use NRT. Nearly all participants (94\%) chose the intervention in Spanish.

All participants were reached at the end of the decision support stage and set up a quit date. All participants requested the first order of NRT. Thirty-six participants (72\%) requested nicotine patches, 10 participants (20\%) requested nicotine gum, and four participants $(8 \%)$ requested nicotine lozenges. Fortytwo participants were reached after their quit day $(84 \%$ retention rate). All participants reported receiving their first order of NRT. A total of $95.23 \%$ participants (40/42) reported doing an NRTassisted attempt on their quit day.

During the 12-week period of the intervention, levels of text messaging interactivity varied among participants: 11 participants $(22 \%)$ had a low interaction with the program (19 text messages), 18 (36\%) had a medium interaction (10-49 text messages), 11 (22\%) had a high interaction (50-99 text messages), and $10(20 \%)$ had a very high interaction ( $\geq 100$ text messages). All participants interacted with the program and had on average of 39.78 (SD 82.70) interactions. Of the 1,989 messages that participants sent to the program, 280 (14.07\%) used keywords. Only 3 participants $(6 \%)$ discontinued the program prior to completion by texting Stop. Of the 50 participants, 33 (66\%) requested a refill of NRT via a text message.

At 12 weeks, 15 participants (30\%) were biochemically verified abstinent (Table 3). The follow-up rate at 12 weeks was $88 \%$. Most participants $(90.90 \%, 40 / 44)$ reported being very satisfied or extremely satisfied with the intervention. Working alliance mean values was 79.2 (SD 9.04), which is considered in the high range of therapeutic alliance in quitting smoking. Self-efficacy mean scores significantly increased $(n=41)$ from 33.98 (SD 10.36 ) at baseline to 40.05 (SD 17.65) at follow-up $(p=0.04$ ). Cessation at week 12 by gender, education level, health insurance cover, and smoking pattern is shown in Table 4 . None of these characteristics was significantly associated with cessation. 
TABLE 1 | Readability results of text messages.

\begin{tabular}{|c|c|c|c|c|c|c|}
\hline \multirow[t]{2}{*}{ Stage } & \multicolumn{3}{|c|}{ Flesch-Kincaid score (English) } & \multicolumn{3}{|c|}{ Fernández Huerta (Spanish) } \\
\hline & Score & Level & Grade level & Score & Level & Grade level \\
\hline Decision support & 74.23 & Fairly easy & 7th grade & 78.00 & Quite easy & 6 th grade \\
\hline Pre-quit & 81.00 & Easy & 6th grade & 83.40 & Easy & 5 th grade \\
\hline Quit-day & 80.10 & Easy & 6th grade & 84.58 & Easy & 5 th grade \\
\hline Post-quit intensive & 76.19 & Fairly easy & 7th grade & 80.65 & Easy & 5 th grade \\
\hline Post-quit maintenance & 77.77 & Fairly easy & 7th grade & 82.20 & Easy & 5 th grade \\
\hline Health & 86.46 & Easy & 6th grade & 90.56 & Very easy & 4 th grade \\
\hline Family & 84.75 & Easy & 6th grade & 88.85 & Easy & 5 th grade \\
\hline Patch & 82.09 & Easy & 6th grade & 86.22 & Easy & 5 th grade \\
\hline Lozenge & 76.58 & Fairly easy & 7th grade & 80.86 & Easy & 5 th grade \\
\hline Gum & 73.41 & Fairly easy & 7th grade & 77.80 & Quite easy & 6 th grade \\
\hline Crave & 79.91 & Fairly easy & 7th grade & 80.11 & Easy & 5 th grade \\
\hline Stress & 82.19 & Easy & 6th grade & 84.44 & Easy & 5 th grade \\
\hline Alcohol & 84.30 & Easy & 6th grade & 86.12 & Easy & 5 th grade \\
\hline Slip up & 81.22 & Easy & 6th grade & 83.78 & Easy & 5th grade \\
\hline Average & 80.01 & Easy & 6th grade & 83.39 & Easy & 5th grade \\
\hline
\end{tabular}

\section{DISCUSSION}

To our knowledge, this is the first culturally- and linguistically adapted smoking cessation text messaging intervention for Latino smokers. In this study, participants expressed high levels of interest in using NRT combined with high engagement in the text messaging program, with $100 \%$ requesting NRT at baseline. Two-thirds of participants (66\%) requested additional NRT via the text messaging program, suggesting that participants completed at least a 4-week course of medication. Finally, the $30 \%$ smoking cessation rate seen at week 12 (end of treatment) is consistent with end-of-treatment cessation rates seen in trials that combine NRT with substantial in-person counseling (39). This level of interest and encouraging abstinence with use of NRT is particularly promising given few clinical trials have included pharmacotherapy for Latino smokers (14, 40-42), and older studies have suggested limited interest in use of pharmacotherapy generally and NRT specifically among Latinos (7). Current findings suggest high interest and utilization.

\section{Implications for Future Research}

This work demonstrates that it is feasible to recruit Latino smokers, a traditionally hard-to-reach group, into a smoking cessation study. As suggested by Cupertino et al., trained Promotores de Salud were a key resources for recruiting this underserved population (43). Future studies can build upon this community-based approach to conduct tobacco control research among Latinos.

We carefully considered the eligibility criteria with the goal of maximizing participation of Latino smokers. Latinos are among the racial/ethnic minority groups with the highest rates of non-daily smoking (44). In the present study, individuals who smoke more than 3 days a week were eligible to participate. Two non-daily smokers were eligible and enrolled in the study ( $4 \%$ of the total sample). However, smoking $<3$ days a week was the second most common reason for ineligibility $(18.08 \%, 17 / 94)$. Given this relatively high number, and that smoking cessation interventions are almost non-existent for non-daily smokers, it is imperative to design, develop, and implement interventions for this particular group.

Moreover, three subjects were removed from the study after consenting because of not knowing how to read text messages. This decision was based on the rationale that to test the impact of the text messaging intervention in smoking cessation, participants need to know how to read the messages. Future studies that aim to test the impact of text messaging interventions, should include an eligibility criteria in which participants must know how to read text messages.

Four studies have assessed participant interactivity in smoking cessation text messaging programs $(30,45-47)$. Interestingly, participants in our study interacted at higher levels (34.6 text messages per participant throughout the 12 -week period) in this study. Abroms et al. found that among two mostly nonLatino samples of smokers, those with at least one interaction with the program sent an average of 11.8 and 28.4 text messages during a 6 -month period $(45,46)$. Of importance, the interactivity in these studies was keyword-based $(45,46)$. Similar to the studies conducted by Cartujano-Barrera et al. (30) and Cupertino et al. (47), participants in this study mostly sent their own, self-composed text messages rather than relying on keywords for a program response. This finding reinforces the hypothesis that text messaging interactivity via keywords may not be sufficient for smoking cessation among Latinos. The text messaging program shows promise to be a low-cost alternative to in-person or telephone counseling for smoking cessation. Moreover, additional strategies can be implemented to lessen the cost of having trained staff responding to participants' text messages, as took place in 


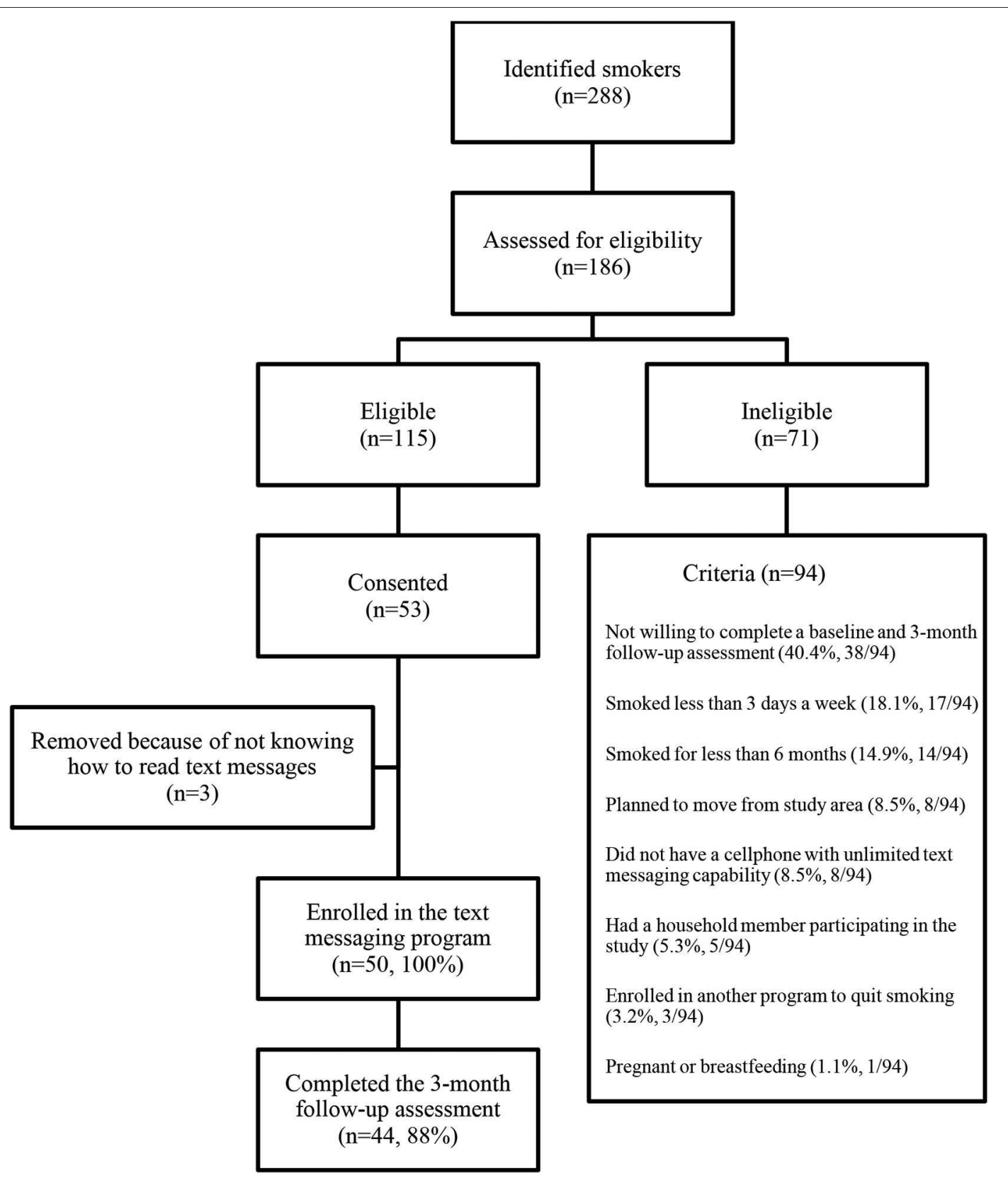

FIGURE 1 | Study design flow diagram.

this study. Messages that participants sent to the program can also inform the development of a text messaging responses codebook, in which responses would be retrieved and sent automatically, thus reducing the need for trained staff responding to participants' messages.

This study provided preliminary evidence that a smoking cessation text messaging intervention significantly increases selfefficacy. As results from myriad cross-sectional and prospective correlational studies show that self-efficacy is a consistent predictor of smoking abstinence (48), the role of text messaging interventions to increase self-efficacy should be further evaluated.
Furthermore, participants in this study reported a very strong therapeutic alliance at end-of-treatment. Greater working alliance predicts early engagement and positive outcomes in many but not all studies on counseling for substance use disorder (49). The role of therapeutic alliance has received some attention in the smoking cessation literature $(50,51)$. However, more research is needed to assess this counseling mechanism, especially in the context of mobile technologies. Future studies should assess therapeutic alliance and self-efficacy as mediators of the presumed treatment effect on smoking abstinence among Latino smokers using smoking cessation technologies. 
TABLE 2 | Baseline characteristics of participants $(n=50)$.

\begin{tabular}{|c|c|}
\hline Characteristics & $n(\%)$ \\
\hline Age, Mean (SD) & $44.8(9.8)$ \\
\hline \multicolumn{2}{|l|}{ Gender } \\
\hline Female & 17 (34\%) \\
\hline Male & $33(66 \%)$ \\
\hline \multicolumn{2}{|l|}{ Marital status } \\
\hline Married/cohabitating & 32 (64\%) \\
\hline Single & $3(6 \%)$ \\
\hline Divorced/separated/widowed & 15 (30\%) \\
\hline \multicolumn{2}{|l|}{ Education level } \\
\hline Less than high school graduate & 20 (40\%) \\
\hline High school graduate & $22(44 \%)$ \\
\hline Technical school & $5(10 \%)$ \\
\hline College graduate & $3(6 \%)$ \\
\hline \multicolumn{2}{|l|}{ Health insurance coverage } \\
\hline No health coverage & 39 (78\%) \\
\hline Private & $8(16 \%)$ \\
\hline Public (Medicare, Medicaid) & $3(6 \%)$ \\
\hline \multicolumn{2}{|l|}{ Country of birth } \\
\hline Mexico & $41(82 \%)$ \\
\hline Guatemala & $3(6 \%)$ \\
\hline United States & $2(4 \%)$ \\
\hline Honduras & $2(4 \%)$ \\
\hline Chile & $1(2 \%)$ \\
\hline Nicaragua & $1(2 \%)$ \\
\hline \multicolumn{2}{|l|}{ Language spoken at home } \\
\hline Only Spanish & $30(60 \%)$ \\
\hline More Spanish than English & $15(30 \%)$ \\
\hline Spanish and English equally & $4(8 \%)$ \\
\hline More English than Spanish & $1(2 \%)$ \\
\hline Only English & 0 \\
\hline \multicolumn{2}{|l|}{ Smoking pattern } \\
\hline Non-daily & $2(4 \%)$ \\
\hline Daily, 1-10 CPD & $34(68 \%)$ \\
\hline Daily, 11-20 CPD & $13(26 \%)$ \\
\hline Daily, 21 or more CPD & $1(2 \%)$ \\
\hline \multicolumn{2}{|l|}{ Time to first cigarette after waking up } \\
\hline$>60 \min$ & $26(52 \%)$ \\
\hline $31-60 \mathrm{~min}$ & $8(16 \%)$ \\
\hline $6-30 \min$ & $5(10 \%)$ \\
\hline$\leq 5 \min$ & $11(22 \%)$ \\
\hline \multicolumn{2}{|c|}{ Attempted to quit smoking in previous year } \\
\hline Yes & 35 (70\%) \\
\hline No & $15(30 \%)$ \\
\hline \multicolumn{2}{|c|}{ Number of 5 closest friends/family who smoke } \\
\hline 0 & $16(32 \%)$ \\
\hline 1 & $12(24 \%)$ \\
\hline 2 & $6(12 \%)$ \\
\hline 3 & $8(16 \%)$ \\
\hline 4 & $3(6 \%)$ \\
\hline 5 & $5(10 \%)$ \\
\hline Self-efficacy (SEQ-12), Mean (SD) & $32.18(10.29)$ \\
\hline
\end{tabular}

CPD, Cigarettes per day; SEQ-12, Self-efficacy questionnaire-12.
TABLE 3 | 12 weeks follow-up outcomes.

\begin{tabular}{|c|c|c|c|}
\hline Outcome & & Statistics & \\
\hline $\begin{array}{l}\text { Biochemically verified abstinence } \\
(n=50), n(\%)\end{array}$ & & $15(30 \%)$ & \\
\hline \multicolumn{4}{|l|}{ Satisfaction $(n=44), n(\%)$} \\
\hline Extremely satisfied & & $16(36.4 \%)$ & \\
\hline Very satisfied & & $24(54.6 \%)$ & \\
\hline Somewhat satisfied & & $4(9.0 \%)$ & \\
\hline Working Alliance $(n=44)$, Mean (SD) & & $79.2(9.04)$ & \\
\hline $\begin{array}{l}\text { Self-efficacy (SEQ-12) }(n=41) \text {, Mean } \\
\text { (SD) }\end{array}$ & & $40.05(17.65)$ & \\
\hline \multicolumn{4}{|l|}{ SEQ-12, Self-efficacy questionnaire-12. } \\
\hline \multicolumn{4}{|c|}{ TABLE 4 | Associations between smoking cessation and sample characteristics. } \\
\hline Characteristics & $\begin{array}{c}\text { Total } \\
(n=50)\end{array}$ & $\begin{array}{l}\text { Quit smoking } \\
\qquad(n=15)\end{array}$ & $p$-value \\
\hline \multicolumn{4}{|l|}{ Gender } \\
\hline Female & 17 & $4(23.5 \%)$ & $0.533^{\mathrm{a}}$ \\
\hline Male & 33 & $11(33.3 \%)$ & \\
\hline \multicolumn{4}{|l|}{ Education level } \\
\hline Less than high school graduate & 20 & $8(40.0 \%)$ & $0.228^{b}$ \\
\hline High school graduate & 22 & $6(27.3 \%)$ & \\
\hline Technical school & 5 & $1(20.0 \%)$ & \\
\hline College graduate & 3 & $0(0 \%)$ & \\
\hline \multicolumn{4}{|l|}{ Health insurance coverage } \\
\hline No & 39 & $13(33.3 \%)$ & $0.468^{\mathrm{C}}$ \\
\hline Private & 8 & $2(25.0 \%)$ & \\
\hline Public (Medicare, Medicaid) & 3 & $0(0 \%)$ & \\
\hline \multicolumn{4}{|l|}{ Smoking pattern } \\
\hline Non-daily & 2 & $1(50 \%)$ & $0.507^{d}$ \\
\hline Daily, 1-10 CPD & 34 & $11(32.4 \%)$ & \\
\hline Daily, 11-20 CPD & 13 & $3(23.6 \%)$ & \\
\hline Daily, 21 or more CPD & 1 & $0(0 \%)$ & \\
\hline
\end{tabular}

CPD, Cigarettes per day.

${ }^{a}$ Fisher's exact test.

${ }^{b}$ Fisher's exact test. The Education Level variable was dichotomized into "Less than high school graduate" vs. "High school graduate or higher education." The p-value compares these two groups.

"Fisher's exact test. The Health Insurance Coverage variable was dichotomized into "No insurance" vs. "Private or public insurance." The p-value compares these two groups.

"Fisher's exact test. The Smoking Pattern variable was dichotomized into "10 or less CPD" vs. "11 or more CPD." The p-value compares these two groups.

\section{Limitations}

This study had a number of limitations. This was a pilot study with a small sample size and no comparison group was available. Thus, assessing the efficacy of this intervention was not possible. Furthermore, follow-up was limited to a single assessment at the end of treatment at 12 -week, and does not include assessment of sustained behavior change after treatment. Despite these limitations, the study suggests that this intervention holds promise as an effective smoking cessation program for Latino smokers, and further testing in a randomized clinical trial is warranted. 
We recognize while Latinos come from a variety of countries, most Latinos in this study were Mexican. It remains unknown whether these preliminary results can be generalized to the entire Latino population, especially since smoking rates vary significantly by country of origin. For instance, a U.S. populationbased longitudinal study reported that current smoking rates was highest among Puerto Ricans (men 35.0\% and women 32.6\%) and Cubans (men $31.3 \%$ and women $21.9 \%$ ), with significantly high smoking intensity measured by pack-years and cigarettes per day among Cubans (52). Dominicans had the lowest smoking prevalence (men $11.0 \%$ and women $11.7 \%$ ). Latinos of other national backgrounds had smoking rates between these groups, and typically higher among men compared to women. Moreover, Puerto Ricans and Cubans were the least likely to report successful quit attempts compared to other Latino subgroups (53). Finally, participants in this study appeared to be low-acculturated given that the majority of participants spoke only Spanish. Future research should consider assessing the efficacy of this intervention among Latinos with varied acculturation levels.

\section{CONCLUSION}

A culturally- and linguistically-adapted smoking cessation text messaging intervention for Latinos was well-accepted by participants, generated high satisfaction and frequent interactivity, significantly increased self-efficacy, produced high therapeutic alliance, and resulted in noteworthy cessation rates at the end of treatment. Moreover, the intervention offers a promising strategy to increase the use and adherence of Nicotine Replacement Therapy. Additional testing in a formal randomized clinical trial is warranted to identify the effectiveness of the intervention and to determine individual characteristics related to treatment response.

\section{REFERENCES}

1. Miller KD, Goding Sauer A, Ortiz AP, Fedewa SA, Pinheiro PS, TortoleroLuna G, et al. Cancer statistics for hispanics/latinos. Cancer J Clin. (2018) 68:425-45. doi: 10.3322/caac. 21494

2. US Census Bureau 2010. Race and Ethnicity. (2010). Available online at: https://www.census.gov/quickfacts/fact/table/US/PST045219 (accessed March 26, 2020).

3. Creamer MR, Wang TW, Babb S, Cullen KA, Day H, Willis G, et al. Tobacco product use and cessation indicators among adults United States, 2018. MMWR Morbid Mortal Weekly Rep. (2019) 68:1013-9. doi: 10.15585/mmwr.mm6845a2

4. Webb Hooper M, Payne M, Parkinson KA. Tobacco cessation pharmacotherapy use among racial/ethnic minorities in the United States: considerations for primary care. Fam Med Commun Health. (2017) 5:193-203. doi: 10.15212/FMCH.2017.0138

5. Soto Mas FG, Papenfuss RL, Jacobson HE, Hsu CE, Urrutia-Rojas X, Kane WM. Hispanic physicians' tobacco intervention practices: a cross-sectional survey study. BMC Public Health. (2005) 5:120. doi: 10.1186/1471-2458-5-120

\section{DATA AVAILABILITY STATEMENT}

The datasets generated for this study are available on request to the corresponding author.

\section{ETHICS STATEMENT}

The study was reviewed and approved by University of Kansas Medical Center Institutional Review Board. Participants provided their written informed consent to participate in this study.

\section{AUTHOR CONTRIBUTIONS}

AC, LS, and EE designed the study. FC-B, MR, and JP-P implemented the study. FC-B, EA-C, MR, JP-P, and FD analyzed the data. FC-B, LS, EA-C, MR, JP-P, PV, FD, DC, EE, and $\mathrm{AC}$ wrote and revised multiple versions of the manuscript and including the final version. All authors contributed to the article and approved the submitted version.

\section{FUNDING}

This work was supported by the National Institute on Minority Health and Health Disparities under grant R41MD010318.

\section{ACKNOWLEDGMENTS}

Special acknowledgment to the research team: Kendra Cruz, MPH, Mitzi Ramirez, and Drew Cox. We also recognize our Promotores de Salud (Catalina Reyes, Karen Yepez-Maza, Lucia Martinez, and Norma Molina) and Agile Health Inc., the text messaging company (Gary Slagle, Scott Werntz, Vova Kagan, and Julieta Rodriguez). Finally, the authors also acknowledge Carolina Uribe, Dora Ponce, Ernesto Suarez, Lilia Castillo, Lucia Jones, and Oscar Monterroso for being part of the Community and Communication Advisory Board.

6. Levinson AH, Borrayo EA, Espinoza P, Flores ET, Pérez-Stable EJ. An exploration of Latino smokers and the use of pharmaceutical aids. Am J Prev Med. (2006) 31:167-71. doi: 10.1016/j.amepre.2006.03.022

7. Levinson AH, Pérez-Stable EJ, Espinoza P, Flores ET, Byers TE. Latinos report less use of pharmaceutical aids when trying to quit smoking. Am J Prev Med. (2004) 26:105-11. doi: 10.1016/j.amepre.2003.10.012

8. Wetter DW, Mazas C, Daza P, Nguyen L, Fouladi RT, Li Y, et al. Reaching and treating Spanish-speaking smokers through the National Cancer Institute's Cancer Information Service. A randomized controlled trial. Cancer. (2007) 109:406-13. doi: 10.1002/cncr.22360

9. Cupertino AP, Cox LS, Garrett S, Suarez N, Sandt H, Mendoza I, et al. Tobacco use and interest in smoking cessation among Latinos attending community health fairs. J Immigr Minor Health. (2011) 13:719-24. doi: 10.1007/s10903-010-9404-y

10. Babb S, Malarcher A, Schauer G, Asman K, Jamal A. Quitting Smoking Among Adults-United States, 2000-2015. Morbid Mortal Weekly Rep. (2017) 65:1457-64. doi: 10.15585/mmwr.mm6552a1

11. Bock BC, Niaura RS, Neighbors CJ, Carmona-Barros R, Azam M. Differences between Latino and non-Latino White smokers in cognitive and behavioral 
characteristics relevant to smoking cessation. Addict Behav. (2005) 30:711-24. doi: 10.1016/j.addbeh.2004.08.017

12. Diverse Racial Ethnic Groups and Nations (DREGAN) Project Team. Tobacco Use in Minnesota: Perspectives From Latino Communities. Eagan, MN: Blue Cross and Blue Shield of Minnesota; Comunidades Latinas Unidas en Servicio; Minnesota Partnership for Action Against Tobacco (2006).

13. Piñeiro B, Diaz DR, Monsalve LM, Martinez U, Meade CD, Meltzer LR, et al. Systematic transcreation of self-help smoking cessation materials for Hispanic/Latino smokers: Improving cultural relevance and acceptability. $J$ Health Commun. (2018) 23:350-9. doi: 10.1080/10810730.2018.1448487

14. de Dios MA, Anderson BJ, Stanton C, Audet DA, Stein M. Project Impact: a pharmacotherapy pilot trial investigating the abstinence and treatment adherence of Latino light smokers. J Substance Abuse Treat. (2012) 43:322-30. doi: 10.1016/j.jsat.2012.01.004

15. Fu SS, Kodl MM, Joseph AM, Hatsukami DK, Johnson EO, Breslau N, et al. Racial/Ethnic disparities in the use of nicotine replacement therapy and quit ratios in lifetime smokers ages 25 to 44 years. Cancer Epidemiol Biomark Prev. (2008) 17:1640-7. doi: 10.1158/1055-9965.EPI-07-2726

16. Fiore MC, Jaén CR, Baker TB, Bailey WC, Benowitz NL, Curry SJ, et al. Treating Tobacco Use and Dependence. Clinical Practice Guideline. Rockville, MD: U.S. Department of Health and Human Services; Public Health Service (2008).

17. Whittaker R, McRobbie H, Bullen C, Rodgers A, Gu Y. Mobile phone-based interventions for smoking cessation (review). Cochrane Database Syst Rev. (2012) 11:1-52. doi: 10.1002/14651858.CD006611.pub3

18. Kong G, Ells DM, Camenga DR, Krishnan-Sarin S. Text messaging-based smoking cessation intervention: A narrative review. Addict Behav. (2014) 39:907-17. doi: 10.1016/j.addbeh.2013.11.024

19. Free C, Phillips G, Watson L, Galli L, Felix L, Edwards P, et al. The effectiveness of mobile-health technologies to improve health care service delivery processes: a systematic review and meta-analysis. PLoS Med. (2013) 10:1-26. doi: 10.1371/journal.pmed.1001363

20. Free C, Knight R, Robertson S, Whittaker R, Edwards P, Zhou W, et al. Smoking cessation support delivered via mobile phone text messaging (txt2stop): a single-blind, randomized trial. Lancet. (2011) 378:49-55. doi: 10.1016/S0140-6736(11)60701-0

21. Rodgers A, Corbett T, Bramley D, Riddell T, Wills M, Lin RB, et al. Do u smoke after txt? Results of a randomised trial of smoking cessation using mobile phone text messaging. Tobacco Control. (2005) 14:255-61. doi: $10.1136 / t c .2005 .011577$

22. Brendryen H, Drozd F, Kraft P. A digital smoking cessation program delivered through internet and cell phone without nicotine replacement (happy ending): randomized controlled trial. J Med Internet Res. (2008) 10:e51. doi: 10.2196/jmir.1005

23. Anderson M. Technology Device Ownership: 2015. Pew Research Center (2015). Available online at: http://www.pewinternet.org/2015/10/29/ technology-device-ownership-2015

24. Hawkins RP, Kreuter M, Resnicow K, Fishbein M, Dijkstra A. Understanding tailoring in communicating about health. Health Educ Res. (2008) 23:454-66. doi: $10.1093 /$ her/cyn004

25. Hall GC, Ibaraki AY, Huang ER, Marti CN, Stice E. A meta-analysis of cultural adaptations of psychological interventions. Behav Ther. (2016) 47:993-1014. doi: 10.1016/j.beth.2016.09.005

26. Michie S, Free C, West R. Characterising the 'Txt2Stop' smoking cessation text messaging intervention in terms of behaviour change techniques. J Smok Cessation. (2012) 7:55-60. doi: 10.1017/jsc.2012.12

27. Cupertino AP, Richter K, Cox LS, Garrett S, Ramirez R, Mujica F, et al. Feasibility of a Spanish/English computerized decision aid to facilitate smoking cessation efforts in underserved communities. $J$ Health Care Poor Underserved. (2010) 21:504-17. doi: 10.1353/hpu.0.0307

28. Cupertino AP, Cartujano-Barrera F, Perales J, Formagini T, RodriguezBolanos R, Ellerbeck EF, et al. "Vive Sin Tabaco... ¡Decídete!” Feasibility and acceptability of an e-health smoking cessation informed decision-making tool integrated in primary healthcare in Mexico. Telemed J e-Health. (2019) 25:425-31. doi: 10.1089/tmj.2017.0299

29. Burrow-Sanchez JJ, Martinez CR, Hops H, Wrona M. Cultural accommodation of substance abuse treatment for Latino adolescents. J Ethnic Substance Abuse. (2011) 10:202-25. doi: 10.1080/15332640.2011.600194
30. Cartujano-Barrera F, Arana-Chicas E, Ramírez-Mantilla M, Perales J, Cox LS, Ellerbeck EF, et al. "Every day I think about your messages": assessing text messaging interaction with Latino smokers. Patient Prefer Adher. (2019) 13:1213-9. doi: 10.2147/PPA.S209547

31. Flesch R. A new readability yardstick. J Appl Psychol. (1948) 32:221-33. doi: $10.1037 / \mathrm{h} 0057532$

32. Kincaid JP, Fishburne RP Jr, Roger RL, Chissom BS. Derivation of New Readability Formulas (Automated Readability Index, Fog Count, and Flesch Reading Ease Formula) for Navy Enlisted Personnel. Memphis, TN: Naval Air Station (1975).

33. Fernández Huerta J. Medidas sencillas de lecturabilidad. Consigna. (1959) 214:29-32.

34. Etter J, Bergman M, Humair J, Perneger T. Development and validation of a scale measuring self-efficacy of current and former smokers. Addiction. (2000) 95:901-13. doi: 10.1046/j.1360-0443.2000.9569017.x

35. SRNT Subcommittee on Biochemical Verification. Biochemical verification of tobacco use and cessation. Nicotine Tobacco Res. (2002) 4:149-59. doi: 10.1080/14622200210123581

36. Kim S. Overview of cotinine cutoff values for smoking status classification. Int J Environ Res Public Health. (2016) 13:1236. doi: 10.3390/ijerph13121236

37. Kokotovic AM, Tracey TJ. Working alliance in the early phase of counseling. J Counsel Psychol. (1990) 1:207-10. doi: 10.1037/0022-0167.37.1.16

38. Corbella S, Botella L, Gómez AM, Herrero O, Pacheco M. Características psicométricas de la versión Española del Working Alliance Inventory-Short (WAI-S) [Psychometric properties of Spanish version of Working Alliance Inventory-Short (WAl-S)]. Anales Psicol. (2011) 27:298-301.

39. Simon JA, Carmody TP, Hudes ES, Snyder E, Murray J. Intensive smoking cessation counseling versus minimal counseling among hospitalized smokers treated with transdermal nicotine replacement: a randomized trial. Am J Med. (2003) 114:555-62. doi: 10.1016/S0002-9343(03)00081-0

40. Leischow SJ, Hill A, Cook G. The effects of transdermal nicotine for the treatment of Hispanic smokers. Am J Health Behav. (1996) 20:304-11.

41. Stanton CA, Papandonatos GD, Shuter J, Bicki A, Lloyd-Richardson EE, de Dios MA, et al. Outcomes of a tailored intervention for cigarette smoking cessation among Latinos living with HIV/AIDS. Nicotine Tobacco Res. (2015) 17:975-82. doi: 10.1093/ntr/ntv014

42. Cartujano-Barrera F, Perales J, Arana E, Cox LS, Yeh H, Ellerbeck EF, et al. Increasing access to smoking cessation treatment among Latino smokers using case management. J Smok Cessation. (2019) 14:168-75. doi: $10.1017 /$ jsc.2019.1

43. Cupertino AP, Suarez N, Cox LS, Fernandez C, Jaramillo ML, Morgan A, et al. Empowering Promotores de Salud to engage in communitybased participatory research. J Immigr Refugee Stud. (2013) 11:24-43. doi: 10.1080/15562948.2013.759034

44. Wortley PM, Husten CG, Trosclair A, Pederson CJ. Nondaily smokers: a descriptive analysis. Nicotine Tobacco Res. (2003) 5:755-9. doi: 10.1080/1462220031000158753

45. Abroms LC, Ahuja M, Kodl Y, Thaweethai L, Sims J, Winickoff JP, et al. Text2Quit: Results from a pilot test of a personalized, interactive mobile health smoking cessation program. J Health Commun. (2012) 17:44-53. doi: 10.1080/10810730.2011.649159

46. Abroms LC, Boal AL, Simmens SJ, Mendel JA, Windsor RA. A randomized trial of Text2Quit: a text messaging program for smoking cessation. Am J Prev Med. (2014) 47:242-50. doi: 10.1016/j.amepre.2014.04.010

47. Cupertino AP, Cartujano-Barrera F, Ramírez M, Rodriguez-Bolanos R, Thrasher JF, Perez-Rubio G, et al. A mobile smoking cessation intervention for Mexico (Vive sin Tabaco. ¡Decídete!): Single-arm pilot study. JMIR Mhealth Uhealth. (2019) 7:e12482. doi: 10.2196/12482

48. Gwaltney CJ, Metrik J, Kahler CW, Shiffman S. Self-efficacy and smoking cessation: a meta-analysis. Psychol Addict Behav. (2009) 23:56-66. doi: $10.1037 / a 0013529$

49. Meier PS, Barrowclough C, Donmall MC. The role of the therapeutic alliance in the treatment of substance misuse: a critical review of the literature. Addiction. (2005) 100:304-16. doi: 10.1111/j.1360-0443.2004.00935.x

50. Klemperer EM, Hughes JR, Callas PW, Solomon LJ. Working alliance and empathy as mediators of brief telephone counseling for cigarette smokers who are not ready to quit. Psychol Addict Behav. (2017) 31:130. doi: $10.1037 / \mathrm{adb} 0000243$ 
51. Warlick C, Richter KP, Catley D, Gajewski BJ, Martin LE, Mussulman LM. Two brief valid measures of therapeutic alliance in counseling for tobacco dependence. J Substance Abuse Treat. (2018) 86:60-4. doi: 10.1016/j.jsat.2017.12.010

52. Kaplan RC, Bangdiwala SI, Barnhart JM, Castaneda SF, Gellman MD, Lee DJ, et al. Smoking among U.S. Hispanic/Latino adults: the Hispanic community health study/study of Latinos. Am J Prev Med. (2014) 46:496-506. doi: 10.1016/j.amepre.2014.01.014

53. Merzel CR, Isasi CR, Strizich G, Castaneda SF, Gellman M, Maisonet Giachello AL, et al. Smoking cessation among U.S. Hispanic/Latino adults: findings from the Hispanic Community Health Study/Study of Latinos (HCHS/SOL). Prev Med. (2015) 81:412-9. doi: 10.1016/j.ypmed.2015.10.006
Conflict of Interest: The authors declare that the research was conducted in the absence of any commercial or financial relationships that could be construed as a potential conflict of interest.

Copyright (C) 2020 Cartujano-Barrera, Sanderson Cox, Arana-Chicas, Ramírez, Perales-Puchalt, Valera, Díaz, Catley, Ellerbeck and Cupertino. This is an openaccess article distributed under the terms of the Creative Commons Attribution License (CC BY). The use, distribution or reproduction in other forums is permitted, provided the original author(s) and the copyright owner(s) are credited and that the original publication in this journal is cited, in accordance with accepted academic practice. No use, distribution or reproduction is permitted which does not comply with these terms. 